\title{
Effect of Vegetation Height and Volume Scattering on Soil Moisture Classification Using Synthetic Aperture Radar (SAR) Images
}

\author{
Majid Mahrooghy ${ }^{1,2}$, James Aanstoos ${ }^{2}$, Khaled Hasan ${ }^{2}$, Saurabh $\operatorname{Prasad}^{2}$, Nicolas H. Younan ${ }^{1,2}$ \\ ${ }^{1}$ Department of Electrical Engineering, Mississippi State University, Mississippi \\ ${ }^{2}$ Geosystems Research Institute, Mississippi State University, Mississippi
}

\begin{abstract}
Soil moisture monitoring around earthen levees can aid in the detection of vulnerability to potential failure of a levee segment. Estimation and classification of soil moisture from SAR is difficult when the surface is covered with significant vegetation. In levees the soil is typically covered with a uniform layer of grass. An increase in the height of grass creates more volume scattering and degrades the relationship between the backscattering and soil moisture. In this work the effect of different heights of grass on the soil moisture classification of earthen levees is studied. To classify the soil moisture a back propagation neural network is used with the following methodology: (1) segmentation of levee and buffer area from the background; (2) extracting the backscatter and texture features such as GLCM (Grey- Level Co-occurrence Matrix) and wavelet features; (3) training the back propagation neural network classier; (4) testing the area of interest and validation of the results using ground truth data. The preliminary results show that the height of grass has a significant impact on soil moisture classification accuracy. The grass height increase from one month's springtime growth caused the accuracy to decrease by around $20 \%$.
\end{abstract}

Keywords-Synthetic Aperture Radar (SAR); feature extraction; neural networks

\section{INTRODUCTION}

Soil moisture plays an important role in many applications such as agriculture, atmospheric science, and hydrology. The estimation of soil moisture using synthetic aperture radar has been developed in recent decades by many researchers. The radar backscattering coefficients are related by soil moisture, surface roughness, and incidence angles. In addition, the backscatter data also are sensitive to low vegetation and trees. Different approaches have been developed to estimate soil moisture using SAR data [1]. Most empirical models developed are for soils without significant vegetative cover [2], [3], [4]. The presence of vegetation increases the complexity of the backscattering. Our hypothesis is that radar backscatter will be correlated to the vegetation height and the soil moisture beneath the vegetation. In our study area the vegetation is mostly Rye grasses. We collected ground data for both grass height and soil moisture. Surfaces were generated from these point data and then compared with the backscatter to see if any direct relationships could be established between the backscatter, grass height and soil moisture. The study area encompasses portions of levees built along the Mississippi River. Parts of this levee system are occasionally weakened by combinations of extreme meteorological and hydrologic events. These can result in slope failure in the form of slough slides on the riverward side and as sand boils behind the landward slope of the levee. Since increase in soil moisture usually accompanies these failures, monitoring the moisture content can provide an indication of vulnerability and impending failure of a levee segment.

\section{DATA}

The study area is a $4 \mathrm{~km}$ stretch of levee along the lower Mississippi River in the United States. Fig. 1 shows the area of studying for testing and training mode (green and yellow area are the testing and training area, respectively).

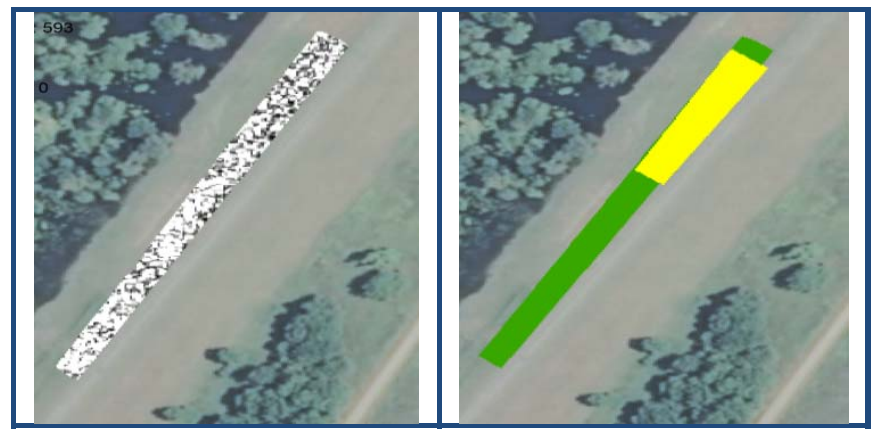

Figure 1. Left: TerraSAR-X data for April 23, 2011 in area of study; Right: the testing (green) and training area (yellow).

Four SAR images taken from the TerraSAR-X sensor in March 10, 21 and April 01, 23 are used as main input data. The TerraSAR-X is a SAR sensor imaging at $9.86 \mathrm{GHz}(3.2 \mathrm{~cm})$ with variable incidence angle and ground resolution. It acquires quad polarized images in experimental mode and single and dual polarized in other situations. All TerraSAR-X images acquired for our study are dual polarized HH/VV. Table I shows the data obtained by the TerraSAR-X for different days. 
TABLE I. TERRASAR-X DATA

\begin{tabular}{|c|c|c|c|c|}
\hline Date (2011) & Mode & Angle & GSD (m) & Area (km) \\
\hline March 10 & HS & 33.77 & 1 & $5 \times 10$ \\
\hline March 21 & SL & 33.38 & 1.5 & $10 \times 10$ \\
\hline April01 & SM & $33.38-34.4$ & 3.5 & $15 \times 50$ \\
\hline April 23 & HS & 33.77 & 1 & $5 \times 10$ \\
\hline
\end{tabular}

Ground truth soil moisture measurements were made using the ThetaProbe manufactured by Delta-T which measures volumetric soil moisture by sensing the apparent dielectric constant of the soil. The ThetaProbe has a configuration of 3 rods surrounding a center rod all of which are inserted into the soil. The difference between voltage at a crystal oscillator (enclosed in the body of the probe) and that reflected by the rods is used to determine the dielectric constant of the soil. The readout from the Theta Probe is percent volumetric water content (VWC\%).

\section{METHODOLOGY}

A block diagram of the soil moisture classification using a back propagation neural network is depicted in Fig. 2. First the SAR images are used as the input data. The SAR images are from different times with different vegetation heights. In the next step, the levee area and the area of study is segmented from the images. Afterward, features are extracted from the segmented area. The features used include the magnitudes of the polarimetric backscattering coefficients $\mathrm{HH}$ and VV as well as their ratios $\mathrm{HH} / \mathrm{VV}$ along with texture features such as window statistics (mean and variance), and wavelet features. Wavelet features used are the mean and standard deviation of the energy of approximation and vertical, horizontal, and diagonal detail coefficients of a two-level decomposition of each pixel and its neighbors (sliding window size 7). Features are extracted and put into a back propagation neural network (BNN). The BNN weights and other parameters are trained based on the ground-truth data. In testing mode, the features at each pixel in the study area are computed and are put into the BNN using the weights derived in training mode. The output then gives the soil moisture classes at each pixel location.

The backpropagation neural network is a multilayer, feedforward network trained by the backpropagation method [5]. It is defined by the input, output, and hidden layers; the weight parameters; and the specified transfer function. The first layer has weights $(\mathrm{W})$ which are applied to the input feature values. The number of hidden layers is dependent on the application. The weights of each hidden layer are applied to the outputs of the previous layer. All layers have biases, and the last layer is the network output. The BNN used in this work includes one hidden layer, and one output neuron. Fig. 3 shows the scheme of the BNN used in this work.

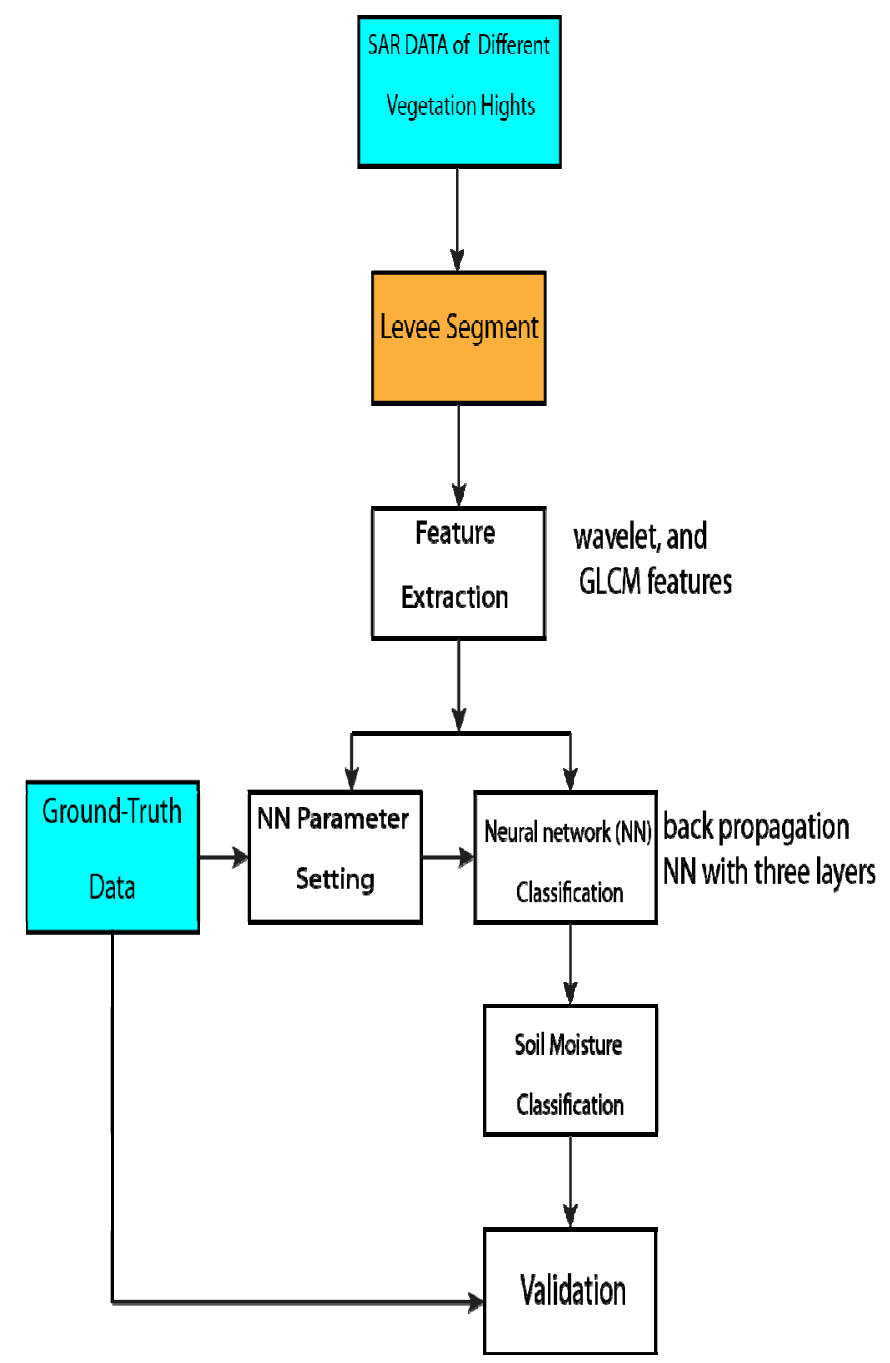

Figure 2. Block diagram of soil moisture classification.

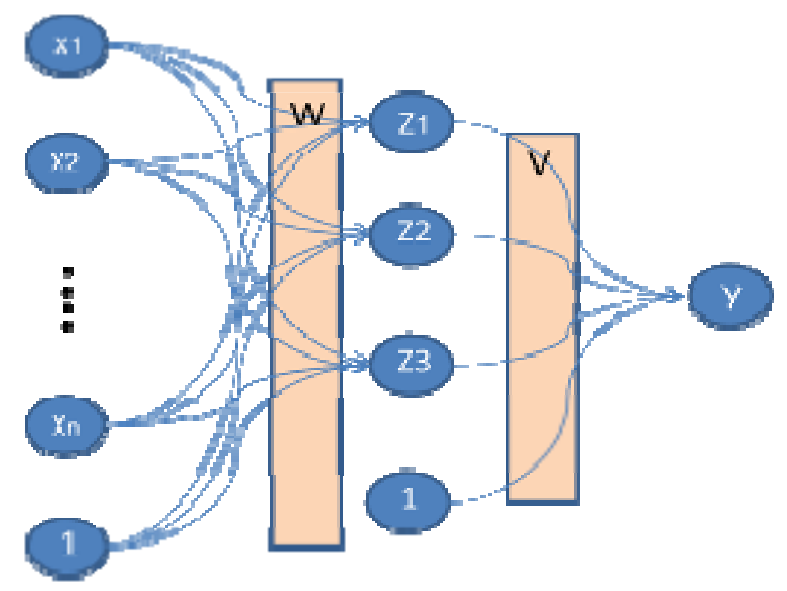

Figure 3. Back propagation neural network with one hidden layer. 


\section{RESULTS AND VALIDATION}

Based on the histogram of the ground-truth soil moisture data from the four days of measurements (March 10, 21 and April $10,23,2011)$, the class labels assigned to a range of soil moisture measures are described in Table II.

\section{TABLE II. CLASS LABEL ASSIGNMENT}

\begin{tabular}{|c|c|}
\hline $\begin{array}{c}\text { Class } \\
\text { Label }\end{array}$ & $\begin{array}{c}\text { Soil Moisture } \\
\text { Range }\end{array}$ \\
\hline Class 1 & $x<23$ \\
\hline Class 2 & $23 \leq x<27$ \\
Class 3 & $27 \leq x<31$ \\
Class 4 & $31 \leq x<35$ \\
Class 5 & $35 \leq x<39$ \\
Class 6 & $39 \leq x<43$ \\
Class 7 & $43 \leq x$ \\
\hline
\end{tabular}

Fig. 4 shows an example of the histogram of the ground-truth soil moisture in the area of study in April 01, 2011. In this example, the range of soil moisture is around 20 to 45 $\mathrm{VWC} \%$.

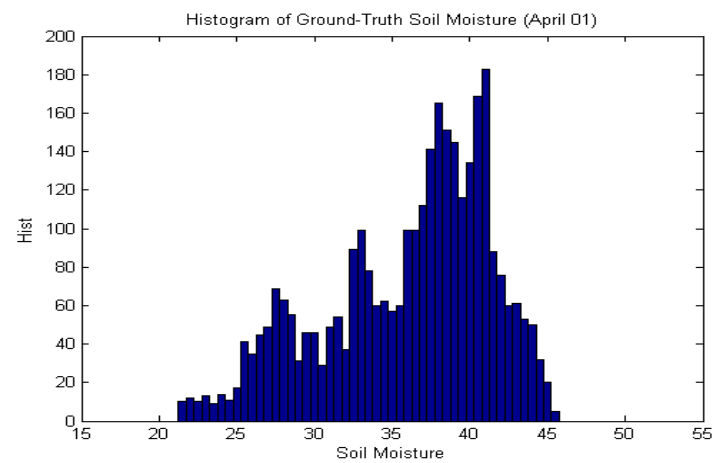

Figure 4. Histogram of ground-truth soil moisture in April 01, 2011.

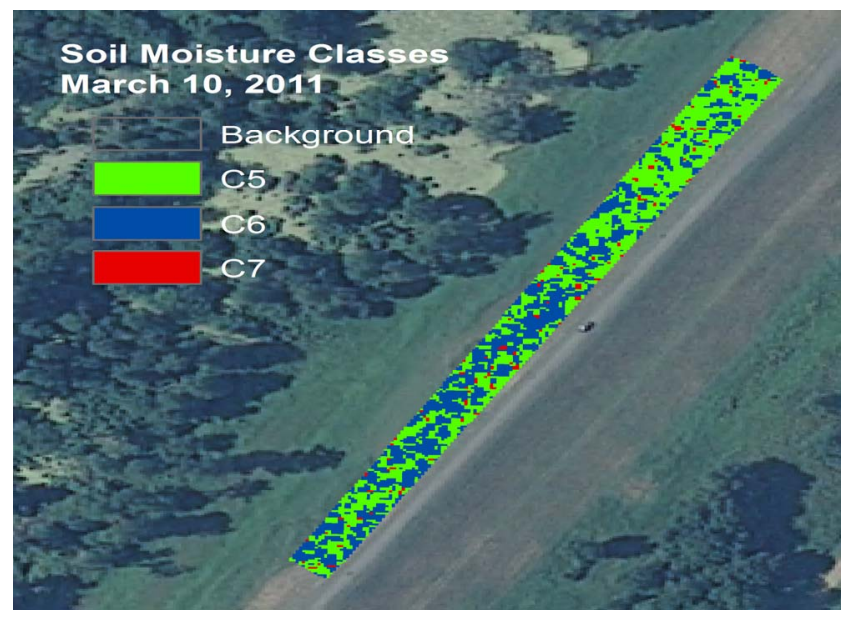

Figure 5. Soil moisture classification using TerraSAR-X for March 10, 2011.
Fig 5 shows the soil moisture classification for Mar 10, 2011 using TerraSAR-X. As seen in this figure, the class ranges of soil moisture are $\mathrm{C} 5, \mathrm{C} 6$, and $\mathrm{C} 7$. The range of class labels is showing the high soil moisture on this day.

TABLE III. CONFUSION MATRIX FOR MARCH 10, 2011

\begin{tabular}{|c|c|c|c|c|}
\hline Estimate & C5 & C6 & C7 & Accuracy \\
\hline C5 & 784 & 692 & 39 & 0.5 \\
\hline C6 & 1633 & 1456 & 99 & 0.46 \\
\hline C7 & 337 & 182 & 15 & 0.03 \\
\hline Accuracy & 0.28 & 0.62 & 0.09 & 0.4 \\
\hline
\end{tabular}

Table III depicts the validation of the soil classification using the SAR data against ground-truth classes for this image. The overall accuracy of classification is $40 \%$.

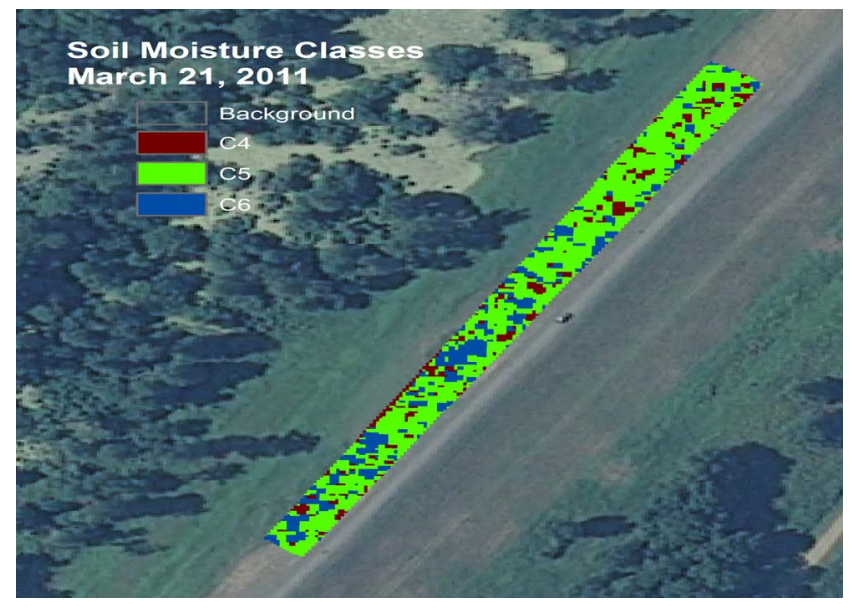

Figure 6. Soil moisture classification using TerraSAR-X in March 21, 2011.

Fig. 6 shows the soil moisture classification using TerraSAR-X for March 21, 2011. Only three classes, C4, C5, and C6 are found in this image. Also, Table IV depicts the validation result (confusion matrix) of the soil moisture classification versus the ground-truth soil moisture classes. As can be seen, the overall classification accuracy is $62 \%$ for this image.

TABLE IV. CONFUSION MATRIX FOR MARCH 21, 2011

\begin{tabular}{|c|c|c|c|c|}
\hline Estimate & C 4 & C5 & C6 & Accuracy \\
\hline C4 & 0 & 0 & 0 & 0 \\
\hline C5 & 493 & 2897 & 737 & 0.7 \\
\hline C6 & 137 & 610 & 377 & 0.33 \\
\hline Accuracy & 0 & 0.82 & 0.33 & 0.62 \\
\hline
\end{tabular}




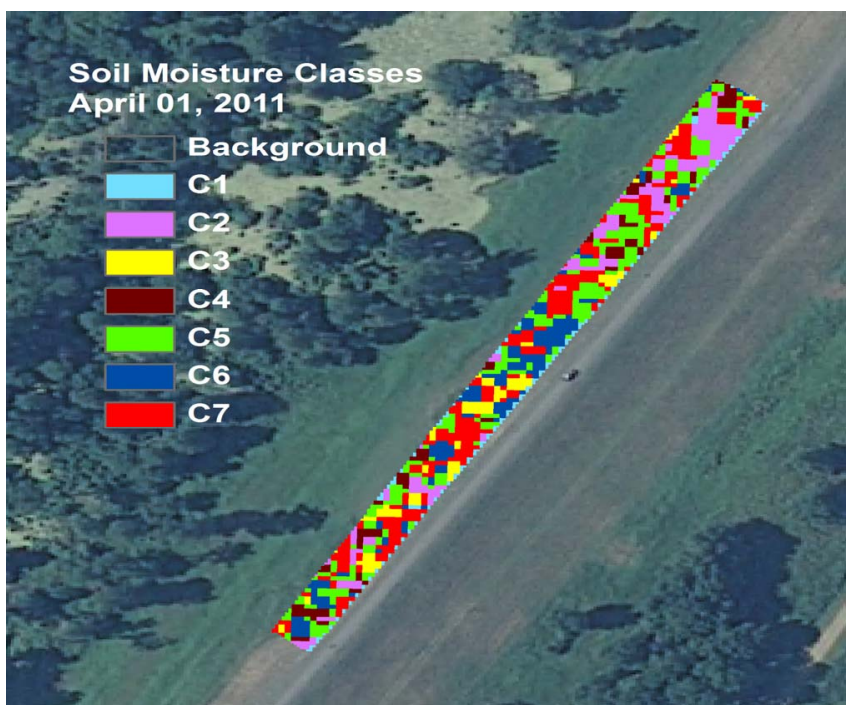

Figure 7. Soil moisture classification using TerraSAR-X in April 01, 2011.

Fig. 7 and 8 depict the soil moisture classification using TerraSAR-X for April 01 and April 23, 2011, respectively.

Soil moisture classification covers almost all ranges of class labels in these images. That is, very low to very high soil moistures are found in the area of study for these times.

In April, the vegetation has grown more than March so the height of vegetation increases and also it is bigger than that of in March. Increase in height of the vegetation creates more volume scattering and this is likely to impact the relationship between SAR backscatter and soil moisture values.

Tables V and IV show the confusion matrix of the result of soil moisture classification for April 01 and 23, 2011 respectively. The overall accuracy for April 01 is $22 \%$ and for April 23 is $16 \%$. These tables show less soil moisture classification accuracy compared to March (Tables III and IV).

TABLE V. CONFUSION MATRIX FOR APRIL 01, 2011

\begin{tabular}{|c|c|c|c|c|c|c|c|c|}
\hline & C1 & C2 & C3 & C4 & C5 & C6 & C7 & Accuracy \\
\hline C1 & 21 & 40 & 6 & 6 & 51 & 15 & 28 & 0.12 \\
\hline C2 & 10 & 71 & 0 & 16 & 11 & 10 & 24 & 0.5 \\
\hline C3 & 14 & 109 & 6 & 22 & 112 & 6 & 33 & 0.02 \\
\hline C4 & 5 & 83 & 15 & 31 & 147 & 0 & 114 & 0.07 \\
\hline C5 & 12 & 179 & 22 & 93 & 220 & 12 & 152 & 0.31 \\
\hline C6 & 80 & 211 & 204 & 194 & 487 & 462 & 659 & 0.2 \\
\hline C7 & 3 & 102 & 150 & 84 & 266 & 266 & 350 & 0.28 \\
\hline Accuracy & 0.14 & 0.09 & 0.01 & 007 & 0.17 & 06 & 0.26 & 0.22 \\
\hline
\end{tabular}

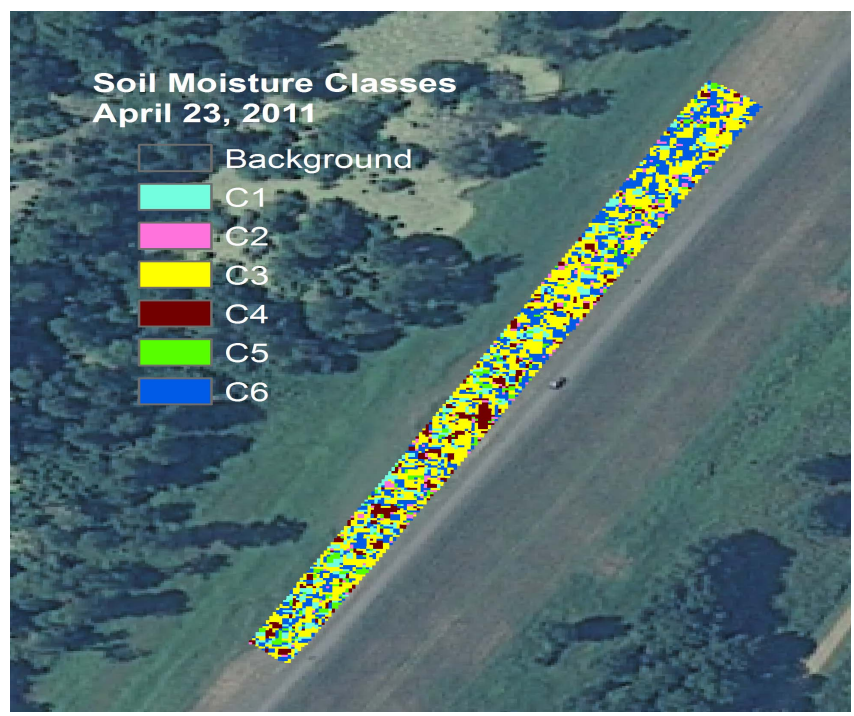

Figure 8. Soil moisture classification using TerraSAR-X in April 23, 2011.

This might be due to the increase in the height of vegetation and resulting increase in the amount of volume scattering in April.

TABLE VI. CONFUSION MATRIX FOR APRIL 23, 2011

\begin{tabular}{|c|c|c|c|c|c|c|}
\hline & C1 & C2 & C3 & C4 & C6 & Accuracy \\
\hline C1 & 96 & 31 & 294 & 24 & 186 & 0.14 \\
\hline C2 & 8 & 10 & 74 & 6 & 59 & 0.05 \\
\hline C3 & 24 & 14 & 192 & 18 & 106 & 0.52 \\
\hline C4 & 46 & 32 & 329 & 50 & 248 & 0.11 \\
\hline C5 & 174 & 65 & 818 & 75 & 449 & 0.04 \\
\hline C6 & 207 & 43 & 593 & 90 & 397 & 0.27 \\
\hline Accuracy & 0.17 & 0.05 & 0.08 & 0.28 & 0.27 & 0.16 \\
\hline
\end{tabular}

\section{SUMMARY AND CONCLUSION}

In this study, we utilized TerraSAR-X images to classify soil moisture along a levee. Soil moisture classification around levees can help in the detection of vulnerability to potential failure of a levee segment. Soil moisture classification from SAR is difficult when the surface is covered with significant vegetation. In this work, SAR images from different dates corresponding to different vegetation heights were used in a soil moisture classification methodology to investigate the effect of the vegetation height on accuracy. The results show that the soil moisture classification accuracy from the April dates is lower than those in March. Since the vegetation in 
April is taller than in March (note that levee grasses are not mowed very often), it can be inferred that the increased volume scattering resulting from the taller vegetation degrades the relationship between the SAR back scattering and the soil moisture.

\section{Acknowledgment}

This work was funded by the Department of Homeland Security Southeast Region Research Initiative (SERRI) at the Department of Energy's Oak Ridge National Laboratory.

\section{REFERENCES}

[1] I. Hajnsek, T. Jagdhuber, H. Schon, K.P. Papathanassiou, "Potential of Estimating Soil Moisture Under Vegetation Cover by Means of PolSAR," Geoscience and Remote Sensing, IEEE Transactions on, vol.47, no.2, pp.442-454, Feb. 2009.

[2] Y. Oh, K. Sarabandi, and F. T. Ulaby, "An empirical model and an inversion technique for radar scattering from bare soil surfaces", IEEE Trans. Geosci. Remote Sensing, vol. 30, pp.370 -382 1992 .

[3] Y. Oh,, "Quantitative retrieval of soil moisture content and surface roughness from multipolarized radar observations of bare soil surfaces," Geosciences and Remote Sensing, IEEE Transactions on, vol.42, no.3, pp. 596- 601, March 2004.

[4] P. C. Dubois, J. van Zyl, and E. T. Engman, "Measuring soil moisture with imaging radar", IEEE Trans. Geosci. Remote Sensing, vol. 33, pp.916 -926, 1995

[5] L.V. Fausett, Fundamentals of Neural Networks: Architectures, Algorithms And Applications, Prentice Hall, 1993. 